\title{
Cauză rară de obstrucție de tract digestiv superior - importanța unei abordări multidisciplinare
}

\author{
Livia E. Brezeanu', Oana M. Guță ${ }^{1}$, Raluca M. Vlad' ${ }^{1,2}$, Anatolie Nidelcu', \\ Mirela Pavelescu ${ }^{1,2}$, Daniela Păcurar ${ }^{1,2}$ \\ ${ }^{1}$ Spitalul Clinic de Urgență pentru Copii „Grigore Alexandrescu“, București, România \\ ¿Universitatea de Medicină și Farmacie "Carol Davila”, București, România
}

\begin{abstract}
REZUMAT
Introducere. Sindromul de arteră mezenterică superioară este o cauză rară de obstrucție intestinală.

Prezentare de caz. Un adolescent în vârstă de 17 ani a fost spitalizat în iulie 2018 în Departamentul Pediatrie al Spitalului Clinic de Urgență pentru Copii „Grigore Alexandrescu“ din Bucureşti pentru vărsături recurente și epigastralgii. Durerile abdominale au debutat cu 5 ani anterior, sunt prezente cvasiconstant, aparent după apendicectomie, şi de aproximativ un an asociază pirozis, disgeuzie, vărsături recurente și senzație de plenitudine postprandială. Inițial, se stabilește diagnosticul de gastrita acută cu Helicobacter pylori și se inițiază triplă terapie, cu remiterea parțială a simptomatologiei. Din cauza simptomatologiei cronice digestive, pacientul își limitează aportul alimentar, cu scădere ponderală consecutivă. La examenul clinic, se remarcă fenotip marfanoid, deformarea cutiei toracice, abdomen excavat, dureros în epigastru și clapotaj. Investigațiile de laborator sunt în limite normale. Tranzitul baritat esogastroduodenal evidențiază stază gastrică importantă cu stomac alungit, dilatare duodenală cu pasaj distal lent. Ecografia abdominală arată reducerea marcată a distanței aorto-mezenterice. La endoscopia digestivă superioară se observă reziduu baritat la 24 de ore de la efectuarea tranzitului și spasm piloric, fiind imposibil pasajul în duoden. Computer tomografia abdominală confirmă obstrucția intestinală la nivelul celei de-a treia porțiuni duodenale prin compresie vasculară la nivelul unghiului aorto-mezenteric, descoperire radiologică specifică sindromului de arteră mezenterică superioară. Se practică tratament chirurgical laparoscopic, cu evoluție postoperatorie favorabilă.

Concluzii. Deși este o entitate rară, obstrucția duodenală prin pensă aorto-mezenterică trebuie luată în considerare în diagnosticul diferențial al vărsăturilor recurente. Un diagnostic radiologic precoce evită consecințele negative asupra statusului nutrițional și asupra calitații vieții la pacienții cu această patologie.
\end{abstract}

Cuvinte cheie: vărsături recurente, obstrucție duodenală, fenotip marfanoid, pensă aortomezenterică

\section{INTRODUCERE}

Sindromul de arteră mezenterică superioară (sindrom Wilkie, sindrom Cast, pensă aorto-mezenterică, ileus duodenal cronic) este o cauză rară de obstrucție a tractului gastrointestinal superior $(1,2)$. Incidența variază între 0,2 şi $0,78 \%$ în populația adultă, preponderent la sexul feminin, fiind descrise cazuri și la copii mari și adolescenți. Până la momentul actual, au fost descrise 400 de cazuri în literatura de specialitate $(3,4)$. Principalul mecanism fiziopatologic implicat este reducerea unghiului între artera mezenterică superioară și aorta abdominală ( $<22$ grade), ceea ce duce la compresia porțiunii 3 duodenale sau a venei renale stângi (5).
Prezentarea clinică include simptomatologie digestivă acută (obstrucție duodenală, varicocel stâng) sau cronică (durere epigastrică postprandială, sațietate precoce, scădere ponderală). Sindromul Wilkie poate fi de cauză congenitală sau dobândită. În formele congenitale, există o scurtare anatomică a ligamentului Treitz. În formele dobândite, există o reducere a țesutului adipos perivascular în regiunea aorto-mezenterică (6). Dintre factorii predispozanți în apariția sindromului, sunt citați: bolile debilitante, sindroamele de malabsorbție, corectarea chirurgicală a scoliozei și alte cauze de scădere ponderală importantă (7). 


\section{PREZENTARE DE CAZ}

Autorii prezintă cazului unui adolescent în vârstă de 17 ani, internat în Secția Pediatrie 3 a Spitalului Clinic de Urgență pentru Copii „Grigore Alexandrescu" din Bucureşti în iunie 2018 pentru episoade recurente de vărsături asociate cu epigastralgii și senzație de plenitudine postprandială. Din antecedentele personale patologice ale pacientului, reținem: apendicectomie (variantă anatomică de apendice retrohepatic) complicată cu peritonită cu 5 ani anterior, astigmatism diagnosticat la 12 ani, pectus excavatum complicat cu insuficiență respiratorie cronică de tip restrictiv, corectat chirurgical cu tijă metalică toracică extrasă cu o lună anterior admisiei curente. Din antecedentele heredocolaterale, menţionăm că tatăl pacientului este cunoscut cu defect de sept atrial și prolactinom.

Adolescentul prezintă durere abdominală intermitentă de aproximativ 5 ani, aparent după apendicectomie, iar în ultimul an asociază pirozis, disgeuzie, vărsături recurente și plenitudine postprandială. Inițial, este diagnosticat cu gastrită acută cu Helicobacter pylori și se inițiază tripla terapie, cu remiterea parțială a simptomatologiei. În evoluție, simptomele reapar în iunie 2018. Se efectuează în ambulator endoscopie digestivă superioară, care evidenţiază stază gastrică și test rapid la urează negativ pentru Helicobacter pylori. Pentru boala de reflux gastroesofagian și tulburări de motilitate esofagiană, s-a recomandat tratament la domiciliu cu inhibitori de pompă de protoni și prokinetice, dar simptomatologia persistă, iar pacientul este internat pentru investigații suplimentare. În ultimul an, din cauza simptomatologiei digestive cro- nice, pacientul își reduce progresiv aportul alimentar cu scădere ponderală consecutivă de peste $10 \mathrm{~kg}$. La examenul clinic, ne aflăm în fața unui adolescent cu hipotrofie ponderală (greutatea pentru vârstă și IMC pentru vârstă - sub percentila 3) cu statură în limite normale (înălţimea pentru vârstă - percentila 50).

La examenul clinic, se observă abdomenul excavat, dureros în epigastru, cu clapotaj la palpare. Pacientul asociază mai multe trăsături particulare care pot fi grupate în fenotipul marfanoid (cifoscolioză, pectus excavatum, hipermobilitate articulară, dolicostenomelie și arahnodactilie). Examenul oftalmologic și cel cardiologic au fost în limite normale.

S-au efectuat analize de laborator: hemogramă, transaminaze, enzime pancreatice, uree, creatinină, ionogramă, hormoni tiroidieni şi anticorpi antitransglutaminază tisulară, toate acestea fiind în limite normale.

S-au luat în considerare mai multe diagnostice diferențiale: boală de reflux gastroesofagian, tulburări de motilitate esofagiană, gastrită acută, ulcer gastric sau duodenal, pancreatită acută, bride postoperator, afecţiuni neoplazice.

Pentru a exclude cauze mecanice de obstrucție intestinală, s-au efectuat investigații radiologice. Tranzitul esogastroduodenal a evidențiat stază gastrică importantă, stomac elongat, cu polul inferior localizat distal de creasta iliacă și dilatarea celei de-a doua porțiuni duodenale, cu pasaj distal lent (figura 1).

Ecografia abdominală a arătat reducerea distanței aorto-mezenterice în dreptul celei de-a treia porțiuni duodenale $(4 \mathrm{~mm})$, cu dilatare anterogradă a duodenului supraiacent (figura 2).

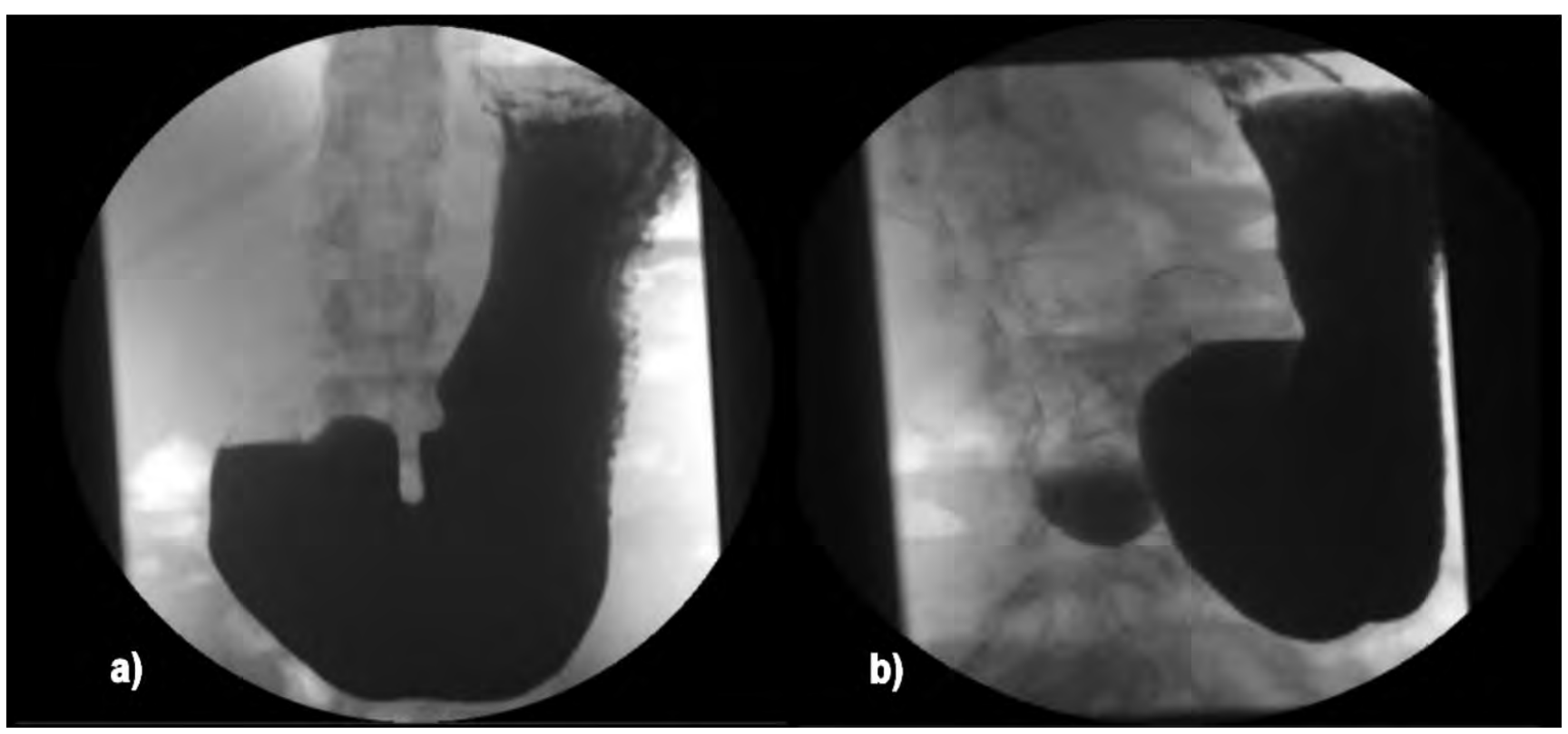

FIGURA 1. Tranzit esogastroduodenal: (a) Stomac alungit, stază gastrică importantă (b) Dilatarea celei de-a doua porțiuni duodenale, pasaj distal lent 

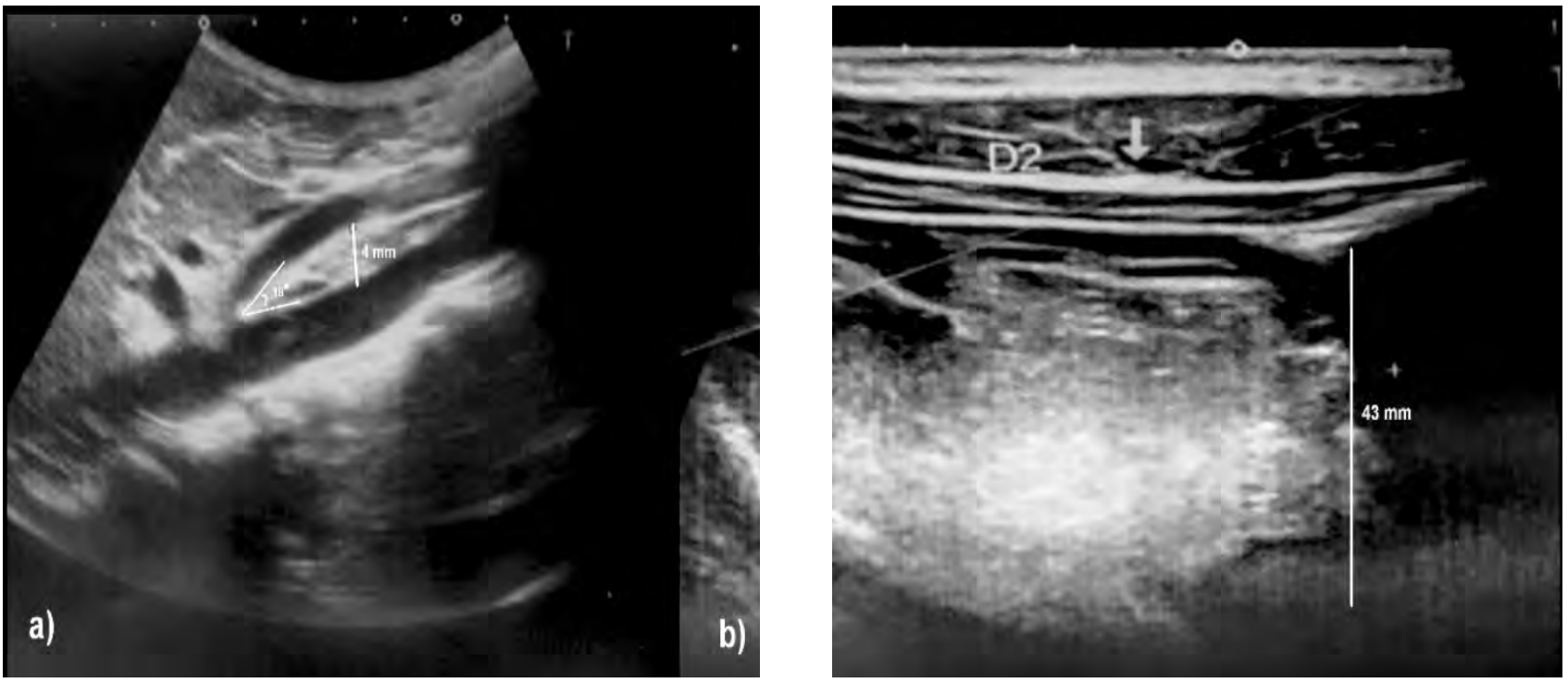

FIGURA 2. Ecografie abdominală: (a) Reducerea distanței aorto-mezenterice la nivelul porțiunii 3 duodenale (b) Dilatarea porțiunii 2 duodenale

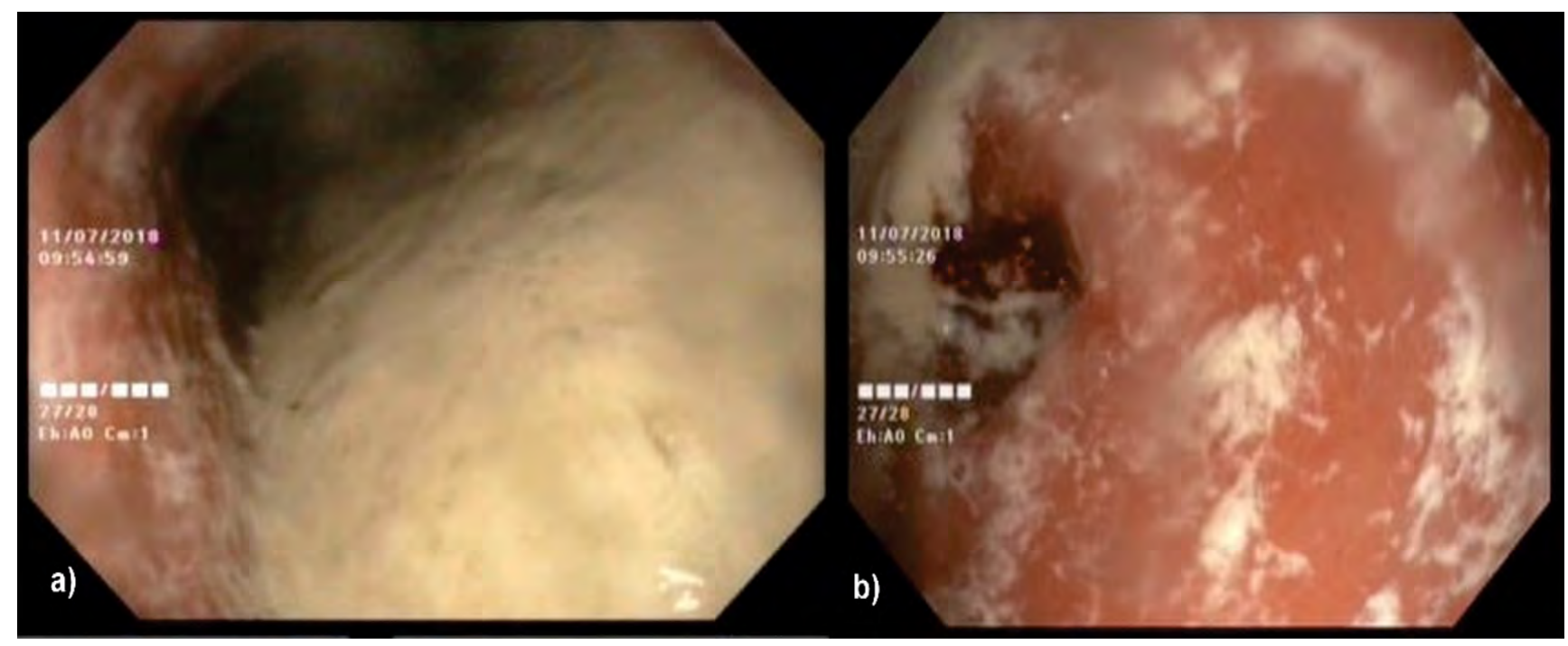

FIGURA 3. Endoscopie digestivă superioară: (a) Reziduu baritat în stomac b) Spasm piloric

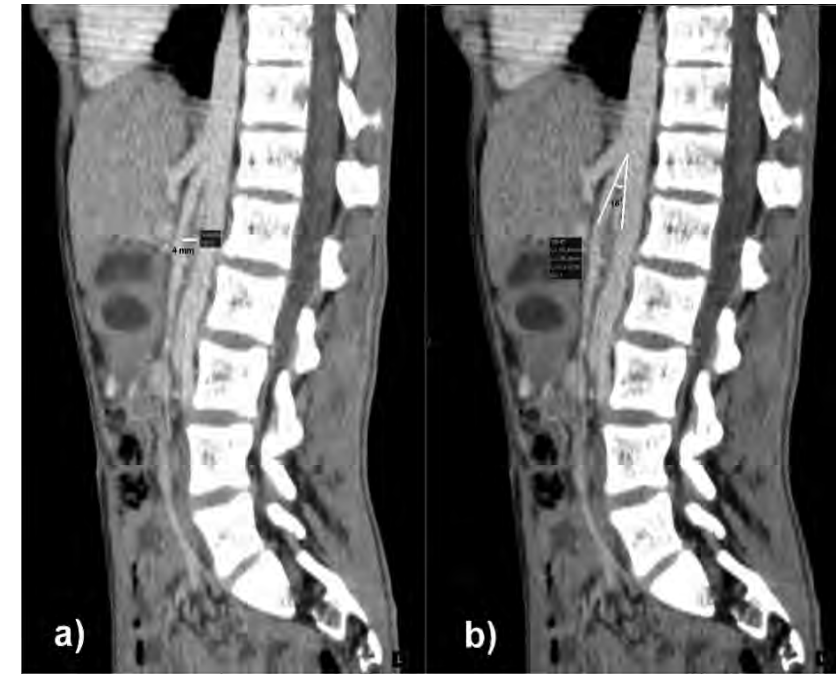

FIGURA 4. CT abdominal cu substanță de contrast: (a) Distanță aorto-mezenterică $=4 \mathrm{~mm}$ (b) Unghi aorto-mezenteric $=18^{\circ}$

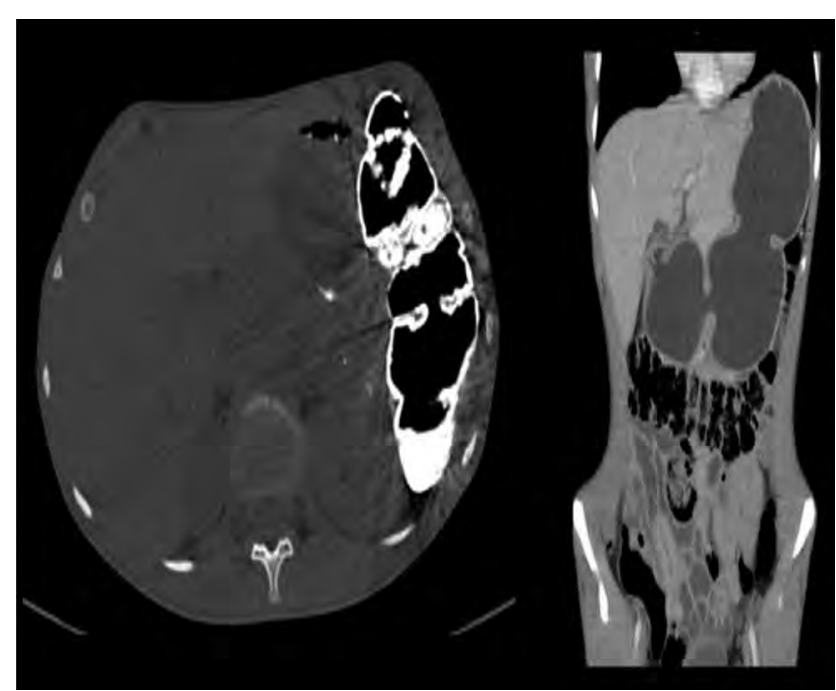

FIGURA 5. CT abdominal cu substanță de contrast - Dilatație a stomacului şi duodenului 
La 24 de ore de la efectuarea tranzitului baritat, se practică endoscopia digestivă superioară, care evidențiază reziduu gastric important cu substanță baritată și spasm piloric, care nu permite avansarea tubului de endoscopie la nivelul duodenului (figura 3).

Computer tomografia abdominală (efectuată după trei zile, din cauza prezenţei substanţei de contrast baritate în stomac) confirmă compresia vasculară prin pensă aorto-mezenterică la nivelul porțiuni 3 duodenale: distanța aorto-mezenterică $4 \mathrm{~mm}$, unghi aortomezenteric 18 grade (figura 4). Se observă, de asemenea, dilatarea importantă a stomacului și a duodenului superior de compresie (figura 5).

Având în vedere simptomatologia cronică și impactul negativ consecutiv asupra statusului nutrițional și calității vieții, se propune tratamentul chirurgical laparoscopic, însă părinții refuză inițial. Ulterior, pacientul este supus intervenției chirurgicale laparoscopice (deviație intestinală pe ansa Roux en Y) într-o clinică privată, cu evoluție postoperatorie favorabilă (remiterea completă a simptomatologiei și curbă ponderală ascendentă - 10 kg în 6 luni).

\section{DISCUȚII}

Pensa aorto-mezenterică este o entitate rară, cu un număr redus de cazuri descrise până la acest moment în literatura de specialitate. Acesta este primul caz comunicat de autori români la un pacient pediatric.

În cazul prezentat, a fost identificată o consecinţa a acestui sindrom, care devine factor de risc important, cu constituirea unui adevărat cerc vicios fiziopatologic. Scăderea ponderală asociată simptomatologiei cronice digestive menționate a dus la reducerea grăsimii perimezenterice, cu reducerea consecutivă a distanței dintre artera mezenterică și aorta abdominală. Un mecanism asemănător a fost descris la pacienții cu anorexie nervoasă $(8,9)$, la cei cu stări hipercatabolice - trauma (10), la pacienți cu chirurgie bariatrică pentru obezitate morbidă (11) sau la cei cu malabsorbție de diferite cauze. Se descriu cazuri în literatură la pacienți cu infecție HIV în stadii avansate (7).

Un alt factor de risc descris în literatură în special la adolescenți este creșterea staturală rapidă în perioada adolescenței, fără creștere compensatorie în greutate (7). Considerăm acest factor ca fiind implicat în fiziopatologia bolii cazului prezentat. De asemenea, posibila formare a adeziunilor peritoneale postapendicectomie este un posibil factor favorizant în dezvoltarea obstrucției intestinale mecanice. Deformările cutiei toracice la acest pacient (cifoscolioză, pectus excavatum) și intervenția ortopedică recentă sunt alţi factori predispozanți citați în literatură (12).

Simptomele sindromului Wilkie pot fi episodice sau persistente și constau în: greață, vărsături recuren- te, epigastralgii postprandiale, toate acestea făcând parte din tabloul clinic al cazului prezentat. Într-un studiu derulat de-a lungul a două decenii (1985-2005) la Spitalul pentru Copii din Wisconsin (22 de pacienți), $59 \%$ au prezentat dureri abdominale, 50\% greață și vărsături, $32 \%$ sațietate precoce și $18 \%$ anorexie (12).

Un istoric amănunţit și un examen clinic riguros se impun la pacienții pediatrici cu vărsături recurente aresponsive la medicația antiemetică, în special dacă au fost excluse etiologiile frecvente de vărsături precum: toxiinfecțiile alimentare, reflux gastroesofagian, gastrită (13). Tabloul clinic cu sindrom dispeptic recurent, asemănător cu cel al cazului prezentat (pirozis, vărsături recurente, plenitudine postprandială, durere abdominală recurentă, curbă ponderală descendentă), ar trebui să constituie semnale de alarmă pentru clinician.

Un pacient pediatric cu simptome sugestive pentru sindromul de arteră mezenterică superioară necesită investigații endoscopice și radiologice amănunțite precum: computer tomografie, angio-CT, imagistică prin rezonanță magnetică, angiografie, ecografie și endoscopie digestivă superioară $(5,14)$.

Studiile au arătat că măsurarea unghiului și a distanței aorto-mezenterice la ecografia abdominală se corelează strâns cu măsurarea acestora prin computer tomografie (3). În cazul prezentat, ultrasonografia abdominală a fost înalt sugestivă, iar diagnosticul radiologic pozitiv a fost stabilit cu ajutorul computer tomografiei abdominale cu substanță de contrast. În sindromul de arteră mezenterică superioară, a treia porțiune duodenală este comprimată între artera mezenterică superioară și aorta abdominală. Anatomic, în mod normal, în spațiul aorto-mezenteric există țesut limfatic și adipos care mențin o angulație normală între 38 şi 65 grade și o distanță aorto-mezenterică de 10-28 mm (7,15). Unghiul aorto-mezenteric, respectiv distanța aorto-mezenterică în cazul prezentat au fost de 18 grade, respectiv $4 \mathrm{~mm}$, care reprezintă valori mult scăzute.

Opțiunile terapeutice pentru sindromul Wilkie includ tratamentul conservator şi chirurgical. Tratamentul conservator constă în decompresia gastrică cu sondă nazogastrică, corectarea tulburărilor hidroelectrolitice și suport nutriţional enteral prin gavaj sau, în cazuri complicate, nutriţie parenterală totală $(7,16)$. În caz de eșec al tratamentului conservator, este recomandat tratamentul chirurgical. Opțiunile de tratament chirurgical includ: gastrojejunostomia, duodenojejunostomia sau alte proceduri de derivație intestinală. Intervenția chirurgicală se poate realiza clasic sau laparoscopic (17). Printre primele comunicări de sindrom de arteră mezenterică superioară din literatură, studiul condus de Sapkas descrie 6 pacienți cu 
simptomatologie debutată în urma intervenției de corecție ortopedică a deformărilor spinale; dintre aceştia, 5 au fost tratați conservator, un singur caz necesitând duodenojejunostomie laparoscopică (18). Pacientul prezentat a necesitat intervenţie chirurgicală cu derivaţie intestinală, iar evoluția a fost favorabilă postoperator, cu îmbunătățirea statusului nutriţional și a calității vieții.

\section{CONCLUZII}

Deși este o entitate rară, obstrucția duodenală prin pensă aorto-mezenterică trebuie luată în considerare în diagnosticul diferențial al vărsăturilor recurente. Un diagnostic radiologic precoce evită consecințele negative asupra statusului nutrițional și asupra calității vieții la pacienții cu această patologie.

\section{Conflict of interest: none declared Financial support: none declared}

\section{BIBLIOGRAFIE}

1. Dorph MH. The cast syndrome; review of the literature and report of a case. N Engl J Med. 1950;243(12):440.

2. Wilkie DP. Chronic duodenal ileus. Br J Surg. 1921; 9:204.

3. Unal B, Aktaş A, Kemal G, Bilgili Y, Güliter S, Daphan C, Aydinuraz K. Superior mesenteric artery syndrome; $\mathrm{CT}$ and ultrasonography findings. Diagn Interv Radiol (2005)11(2):90-95.

4. Agrawal GA, Johnson PT, Fisherman EK. Multi detector row CT of superior mesenteric artery syndrome. J Clin Gastroenterol. 41 (2007) (1):62-65.

5. Welsch T, Buchler MW. Recalling superior mesenteric artery syndrome. Dig Surg. 24 (2007):149-156.

6. Farina R., Foti PV. Wilkie's syndrome. J Ultrasound. 2017, 20:339-34.

7. Scovell S, Hamdan A. Superior mesenteric artery syndrome, uptodate. com (Accesed on 24.06.2019)

8. Pentlow BD, Dent RG. Acute vascular compression of the duodenum in anorexia nervosa. Br J Surg. 1981;68(9):665.

9. Gwee K, Teh A, Huang C. Acute superior mesenteric artery syndrome and pancreatitis in anorexia nervosa. Australas Psychiatry. 2010; 18(6):523.

10. Smith BM, Zyromski NJ. Superior mesenteric artery syndrome: an underrecognized entity in the trauma population. J Trauma. 2008; 64(3):827.

11. Goitein D, Gagné DJ. Superior mesenteric artery syndrome after laparoscopic Roux-en-Y gastric bypass for morbid obesity. Obes Surg. 2004;14(7):1008.
12. Biank V, Werlin S. Superior mesenteric artery syndrome in children: a 20-year experience. J Pediatr Gastroenterol Nutr. 2006 May; 42(5):522-5.

13. McCollough M, Sharieff GQ. Abdominal pain in children. Pediatr Clin North Am. 2006;53:109e113.

14. Wee JW, Lee TH, Lee JS, Kim WJ. Superior Mesenteric Artery Syndrome Diagnosed with Linear Endoscopic Ultrasound in a Patient with Normal Body Mass Index. Clin Endosc. 2013 Jul;46(4):410-3.

15. Lalanne MA, Ocantos JA, Coronil JR, Gentile E, Cabrera MI, Sinclair ME, Seehaus AC, García-Mónaco RD. The aorto-mesenteric angle and its elements: Clinical and imaging features of vascular and gastrointestinal compression syndromes. Proceedings of the European Congress of Radiology (ECR). Vienna, Austria 2013 (poster C-1800).

16. Munns SW, Morrissy RT. Hyperalimentation for superior mesentericartery (cast) syndrome following correction of spinal deformity. J Bone Joint Surg Am. 1984;66(8):1175.

17. Gersin KS, Heniford BT. Laparoscopic duodenojejunostomy for treatment of superior mesenteric artery syndrome. JSLS. 1998; 2(3):281.

18. Sapkas G, O'Brien JP. Vascular compression of the duodenum (cast syndrome) associated with the treatment of spinal deformities. A report of six cases. Arch Orthop Trauma Surg. 1981;98(1):7. 